\title{
Múltiplas estirpes de isolados de Mycobacterium bovis identificados por tipagem molecular em bovinos abatidos em matadouros-frigoríficos ${ }^{1}$
}

\author{
Fernando Alzamora Filho ${ }^{2 *}$, Sidra E.G. Vasconcellos ${ }^{3}$, Harrison M. Gomes ${ }^{3}$, Miriam \\ P. Cavalcante ${ }^{4}$, Philip N. Suffys ${ }^{3}$ e Joselito N. Costa ${ }^{5}$
}

\begin{abstract}
Alzamora Filho F., Vasoncellos S.E.G., Gomes H.M., Cavalcante M.P., Suffys P.N. \& Costa J.N. 2014. [Multiple strains of Mycobacterium bovis isolates identified by molecular typing of bovine animals slaughtered in slaughterhouse.] Multiplas estirpes de isolados de Mycobacterium bovis identificados por tipagem molecular em bovinos abatidos em matadouros-frigoríficos. Pesquisa Veterinária Brasileira 34(2):103-108. Departamento de Ciências Agrárias e Ambientais, Universidade Estadual de Santa Cruz, Rodovia Jorge Amado Km 16, Bairro Salobrinho, Ilhéus, BA 45662-900, Brazil. E-mail: alzafilho@yahoo.com.br

The aim of this study was to use bacteriological and molecular methods to identify Mycobacterium bovis in lesions observed in cattle carcasses during routine post-mortem inspection in slaughterhouses with official inspection service. It was accompanied the slaughter and inspection of 825,394 cattle, healthy ante mortem examination by the official inspection service in ten slaughterhouses in the state of Bahia. Carcasses of 180 cattle presented lesions suggestive of tuberculosis and other lymphadenitis. In bacterial isolation, 25 samples showed dysgonic growth of colonies of creamy-yellow in medium-Stonebrink Leslie. From these isolates, 14 were identified as M. bovis and the multiplex PCR technique spoligotyping was discriminated against eight different spoligotypes of $M$. bovis, seven previously described in the literature and a new spoligotypes without former description. The major spoligotypes was SB0121, with five samples which has been described in Brazil and other countries, followed by two clusters, SB295 and SB1055, with two isolates each. The SB1145 and SB1648 spoligotypes were reported only in Brazil and Denmark, respectively. The spoligotypes SB140 has been found in Brazil, Argentina, Uruguay and Paraguay. These results demonstrate that the spoligotypes obtained are shared, so far, among Brazilian states and among Latin America and Europe. Thus, molecular discrimination of isolates of $M$. bovis by Spoligotyping constitutes a tool for epidemiological studies of bovine tuberculosis in the state of Bahia.
\end{abstract}

INDEX TERMS: Mycobacterium bovis, mycobacteria, molecular epidemiology, spoligotyping, tuberculosis, zoonosis, cattle.

\footnotetext{
${ }^{1}$ Recebido em 4 de setembro de 2013.

Aceito para publicação em 22 de outubro de 2013.

${ }^{2}$ Departamento de Ciências Agrárias e Ambientais, Universidade Estadual de Santa Cruz, Campus Soane Nazaré de Andrade, Pavilhão Jorge Amado, Rodovia Jorge Amado Km 16, Bairro Salobrinho, Ilhéus, BA 45662-900, Brasil.*Autor para correspondência: alzafilho@yahoo.com.br

${ }^{3}$ Laboratório de Biologia Molecular Aplicada à Micobactérias, Fundação Oswaldo Cruz, Av. Brasil 4365, Manguinhos, Rio de Janeiro, RJ 21040-360, Brasil.

${ }^{4}$ Departamento de Patologia e Clínicas, Escola de Medicina Veterinária, Universidade Federal da Bahia (UFBA), Av. Ademar de Barros 500, Ondina, Salvador, BA 40170-110, Brasil.

${ }^{5}$ Centro de Ciências Agrárias, Ambientais e Biológicas, Universidade Federal do Recôncavo Baiano (UFRB), Rua Rui Barbosa 710, Campus Universitário, Cruz das Almas, BA 44380-000, Brasil.
}

RESUMO.- 0 objetivo do presente trabalho foi utilizar métodos bacteriológicos e moleculares para a identificação do Mycobacterium bovis em lesões observadas em carcaças de bovinos durante a inspeção post mortem de rotina em matadouros-frigoríficos com serviço de inspeção oficial. Foi acompanhado o abate e a inspeção de 825.394 bovinos, sadios ao exame ante mortem pelo serviço de inspeção oficial em dez matadouros-frigoríficos do estado da Bahia. Carcaça de 180 bovinos apresentaram lesões sugestivas de tuberculose e por outras linfadenites. No isolamento bacteriano, 25 amostras apresentaram crescimento disgônico de colônias de coloração creme-amareladas em meio de cultura Stonebrink-Leslie. Desses isolados, 14 foram identifi- 
cados como M. bovis PCR multiplex e pela técnica do spoligotyping foram discriminados oito diferentes espoligotipos do $M$. bovis, sendo sete descritos na literatura e um novo spoligotipo sem descrição anterior. 0 espoligotipo majoritário foi o SB0121, com cinco amostras, sendo descrito no Brasil e em outros países, seguidos por dois clusters, SB295 e SB1055, com dois isolados cada. O espoligotipo SB1145 e SB1648 foram referidos apenas no Brasil e Dinamarca, respectivamente. 0 espoligotipo SB140 já foi encontrado no Brasil, Argentina, Uruguai e Paraguai. Estes resultados demonstram que os espoligotipos obtidos são compartilhados, até o momento, entre estados brasileiros e entre países da América Latina e Europa. Sendo assim, a discriminação molecular de isolados de M. bovis através do Spoligotyping constitui-se numa ferramenta para estudos epidemiológicos da tuberculose bovina no Estado da Bahia.

TERMOS DE INDEXAÇÃO: Mycobacterium bovis, micobactéria, epidemiologia molecular, spoligotyping, tuberculose, zonose, bovinos.

\section{INTRODUÇÃO}

A tuberculose bovina é uma zoonose de evolução crônica causada pelo Mycobacterium bovis, que pertence ao Complexo Mycobacterium tuberculosis. Caracteriza-se pelo desenvolvimento de lesões granulomatosas nodulares denominadas tubérculos, que podem estar localizados em qualquer órgão, mas com distribuição predominante no trato respiratório e nos gânglios linfáticos bronquiais e mediastínicos e ocasionalmente nos intestinos, fígado, baço, pleura e peritônio (Brasil 2006, Heinemann et al. 2008).

A tuberculose no homem é causada principalmente pelo Mycobacterium tuberculosis, mas a doença causada por M. bovis tem sido reportada e representa um risco para a saúde pública (Parreiras et al. 2012, Reyes et al. 2012). Em 2011, 8,7 milhões de pessoas adoeceram e 1,4 milhões de óbitos anuais foi determinado pela tuberculose. A maioria dos óbitos ocorre em países de baixa e média renda e está entre as três principais causas de mortes em mulheres entre 15 e 44 anos de idade (WHO 2012).

A importância econômica atribuída à doença bovina está baseada nas perdas diretas resultantes da morte de animais, redução no ganho de peso, diminuição na produção de leite e descarte precoce de animais de elevado valor zootécnico (Lilenbaum 2000, Pacheco et al. 2009).

A pecuária tem se expandido significativamente nas últimas décadas, representando um importante setor na economia do Brasil e o rebanho bovino da Bahia, 10.528.419 cabeças, o equivalente a $36,6 \%$ do efetivo do Nordeste, contribui para a crescente importância do agronegócio no Estado (IBGE 2010). Esse crescimento torna cada vez mais necessário o incremento do controle sanitário nos rebanhos. No Brasil, a tuberculose bovina é endêmica e acomete grande parte das propriedades de leite, devido ao fato dos animais serem submetidos ao confinamento; dados de notificações oficiais indicam uma prevalência média nacional de 1,3\% de animais reagentes à tuberculina no período de 1989-1998. Com o intuito de diminuir a ocorrência da doença nos rebanhos bovinos, o MAPA instituiu em 2001 o Programa Nacional de Controle e Erradicação da Brucelo- se e Tuberculose Bovina (PNCEBT), que tem o objetivo de reduzir a prevalência e incidência da doença (Brasil 2006).

0 inquérito epidemiológico da tuberculose no Estado da Bahia, realizado entre 2008 e 2010, revelou uma prevalência de foco de Tuberculose bovina e de animais reagentes à tuberculina com idade maior ou igual a 24 meses de $1,6 \%$ e $0,21 \%$, respectivamente (Costa 2012). Segundo Araújo (2004), estudos realizados no país, a partir de exames de carcaças em matadouros-frigoríficos, estimaram uma prevalência de tuberculose bovina de 0,17\% em Minas Gerais, 5,16\% no Pará e 0,64\% no Rio Grande do Sul. Esta diferença está relacionada ao grau de desenvolvimento regional, principalmente no que se refere ao estabelecimento de medidas sanitárias no rebanho.

A inspeção post mortem dos animais destinados ao consumo nos abatedouros tem grande importância na vigilância epidemiológica da tuberculose e, por meio desta medida, países endêmicos que possuem satisfatório desempenho nos seus serviços de inspeção nos abatedouros, juntamente com um consolidado programa de erradicação, têm conseguido reduzir a prevalência da doença (De La Rua-Domenech 2006, Kantor \& Ritacco 2006). A identificação de alterações anatomopatológicas características durante a inspeção post mortem nos matadouros-frigoríficos, juntamente com a realização dos métodos diretos de diagnóstico da tuberculose são importantes ferramentas na vigilância epidemiológica da doença (Biffa et al. 2010).

Diversos estudos vêm demonstrando a possibilidade do uso da PCR no diagnóstico da tuberculose bovina, permitindo uma maior acurácia e significativa redução do tempo do diagnóstico em relação aos métodos tradicionais de identificação dos isolados (Zanini et al. 2001, Cardoso et al. 2009, Collins 2011). Estudos epidemiológicos moleculares da tuberculose bovina têm sido utilizados para monitoramento e controle do comércio de animais, bem como para a investigação da origem da infecção (Figueiredo et al. 2011).

Uma combinação que tem se mostrado eficiente para o diagnóstico direto da tuberculose bovina é o isolamento através de bacteriologia clássica, seguido da identificação por métodos moleculares. Uma técnica que vem sendo utilizada é o spoligotyping, que se baseia no polimorfismo de DNA presente em um lócus cromossomal particular, a região de repetição direta (DR), presente apenas nas bactérias do complexo M. tuberculosis. Sendo indicada como técnica de eleição para a comparação de estirpes com poucas cópias de IS 6110, além da diferenciação entre $M$. bovis e $M$. tuberculosis pela ausência e presença, respectivamente, dos espaçadores 39 aos 43 (Kamerbeek et al. 1997, Rodriguez et al. 2004, McLernon et al. 2011). 0 spoligotyping, método rápido e de baixo custo para tipificação e tem sido utilizado com sucesso em alguns estudos com cepas de M. bovis isoladas no Brasil. Também tem demonstrado ser uma metodologia útil para a compreensão da epidemiologia do $M$. bovis em vários países (Haddad et al. 2004, Rodriguez et al. 2004, Collins 2011, Parreiras et al. 2012, Reyes et al. 2012).

A genotipagem do $M$. bovis tem contribuído para um melhor conhecimento da transmissão da tuberculose bovina ou mesmo da compreensão epidemiológica da infecção, que são fundamentais para melhorar na gestão eficaz dos 
sistemas de controle dessa enfermidade (Costa et al. 2010, Figueiredo et al. 2011, McLernon et al. 2011). Desta forma, o objetivo do presente trabalho foi avaliar a diversidade genética, pela técnica de Spoligotyping, de 14 isolados de $M$. bovis provenientes de bovinos abatidos no Estado da Bahia.

\section{MATERIAL E MÉTODOS}

Durante o período de abril de 2009 a abril de 2012, foi acompanhado o abate e a inspeção post mortem de 825.394 bovinos, sadios ao exame ante mortem pelo serviço de inspeção oficial abatidos em 10 matadouros-frigoríficos com serviço de inspeção oficial, localizados em 10 municípios do Estado da Bahia. As lesões sugestivas de tuberculose ou por linfadenites diversas durante a rotina de inspeção das carcaças bovinas foram acondicionadas em frascos com solução saturada de borato de sódio $\left(\mathrm{Na}_{2} \mathrm{~B}_{2} \mathrm{O}_{7} \bullet 10 \mathrm{H}_{2} \mathrm{O}\right.$, $140 \mathrm{~g} / \mathrm{L})$, como meio conservante, o qual preserva as micobactérias por até 60 dias em temperatura ambiente (Richards \& Wright 1983, Rodriguez et al. 2004). Dados referentes à procedência dos animais foram obtidos por meio da Guia de Trânsito Animal (GTA). As amostras foram enviadas para o laboratório de Tuberculose da Escola de Medicina Veterinária e Zootecnia da Universidade Federal da Bahia e foram processadas no prazo máximo de 60 dias para a tentativa de isolamento e identificação de micobactérias. Essas foram descontaminadas pelo cloreto de 1-Hexadecilpiridinio (HPC), inoculadas nos meios de cultura Stonebrink-leslie e Lowenstein-Jensen, incubadas a $37^{\circ} \mathrm{C}$ por até 90 dias e avaliados semanalmente para verificação de colônias sugestivas de micobactérias. As colônias isoladas foram submetidas à coloração de Ziehl-Neelsen para confirmação das características tintoriais de bacilo álcool-ácido resistente (BAAR) (Brasil 2008).

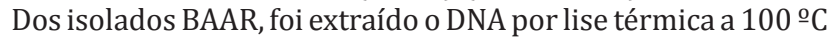
por 30 min. e confirmou-se a identificação de Mycobacterium bovis por PCR multiplex (Warren et al. 2006). A tipificação molecular pelo Spoligotyping foi realizada como o descrito por Kamerbeek et al. (1997). A amplificação da região direta foi realizada num volume final de $50 \mu \mathrm{L}$ com $0,2 \mathrm{mM}$ contendo dNTP $(10 \mathrm{mM}$ Tris- $\mathrm{HCl}$, $\mathrm{pH} 8.0 ; 50 \mathrm{mM} \mathrm{KCl}), 1.5 \mathrm{mM} \mathrm{MgCl}_{2}, 20 \mathrm{pmol}$ de primers para cada iniciador (Dra biotinilado e DRb) e $1 \mathrm{U}$ de Taq DNA polimerase e 10 ng de DNA. A PCR consistiu em uma desnaturação inicial a $96^{\circ} \mathrm{C}$ por 3 min., 20 ciclos de amplificação a $96^{\circ} \mathrm{C}$ por $1 \mathrm{~min}$., $55^{\circ} \mathrm{C}$ por $1 \mathrm{~min}$. e $72^{\circ} \mathrm{C}$ por $30 \mathrm{~s}$, seguido por uma extensão final a $72^{\circ} \mathrm{C}$ por 5 min. 0 DNA de M. bovis BCG e M. tuberculosis Moureau H37Rv foram utilizados como controles positivos e água ultra-pura foi o controle negativo. Os produtos de PCR foram hibridados em membrana contendo 43 oligonucleotídeos de sequências espaçadoras conhecidas. Após incubação com estreptavidina-peroxidase, os espaçadores foram detectados por quimioluminescência. Os padrões polimórficos foram comparados com banco de dados internacional, disponível na literatura (Kremer et al. 1999, Van Embden et al. 2000, Haddad et al. 2001). A nomenclatura adotada para os espoligotipos obtidos foi a mesma que encontra-se disponível no site www.mbovis.org. 0 novo espoligotipo determinado foi nomeado pelos autores.

\section{RESULTADOS}

Do total de 825.394 bovinos abatidos durante a rotina de inspeção em 10 matadouros-frigoríficos, 180 carcaças $(0,02 \%)$ apresentaram nódulos de aspecto caseoso sugestivo de tuberculose (Fig.1) ou por linfadenites por outras causas. As lesões estavam localizadas principalmente em linfonodos da cabeça e pescoço, assim como nos linfonodos torácicos, pulmões, fígado e peritônio.

Na bacteriologia, o crescimento de colônias de coloração creme-amareladas, pequenas, arredondadas, bordas irregulares, superfície granular em meio de cultura Stonebrink-Leslie foi observado em $25(13,9 \%)$ amostras das 180 provenientes de bovinos abatidos em matadouros-frigoríficos no Estado da Bahia. 0 tempo médio observado para o aparecimento das colônias foi de 34 dias, sendo o mínimo de 22 dias e o máximo de 63 dias. Foram submetidos à coloração de Ziehl-Neelsen e todos os esfregaços evidenciaram a presença de bacilos álcool-ácido resistentes. Pela PCR múltiplex, Mycobacterium bovis foi identificado em 14/25 (56\%) isolados. Nas demais amostras, 11/25 (44\%) não apresentaram amplificações das regiões genômicas que caracterizam o complexo M. tuberculosis.

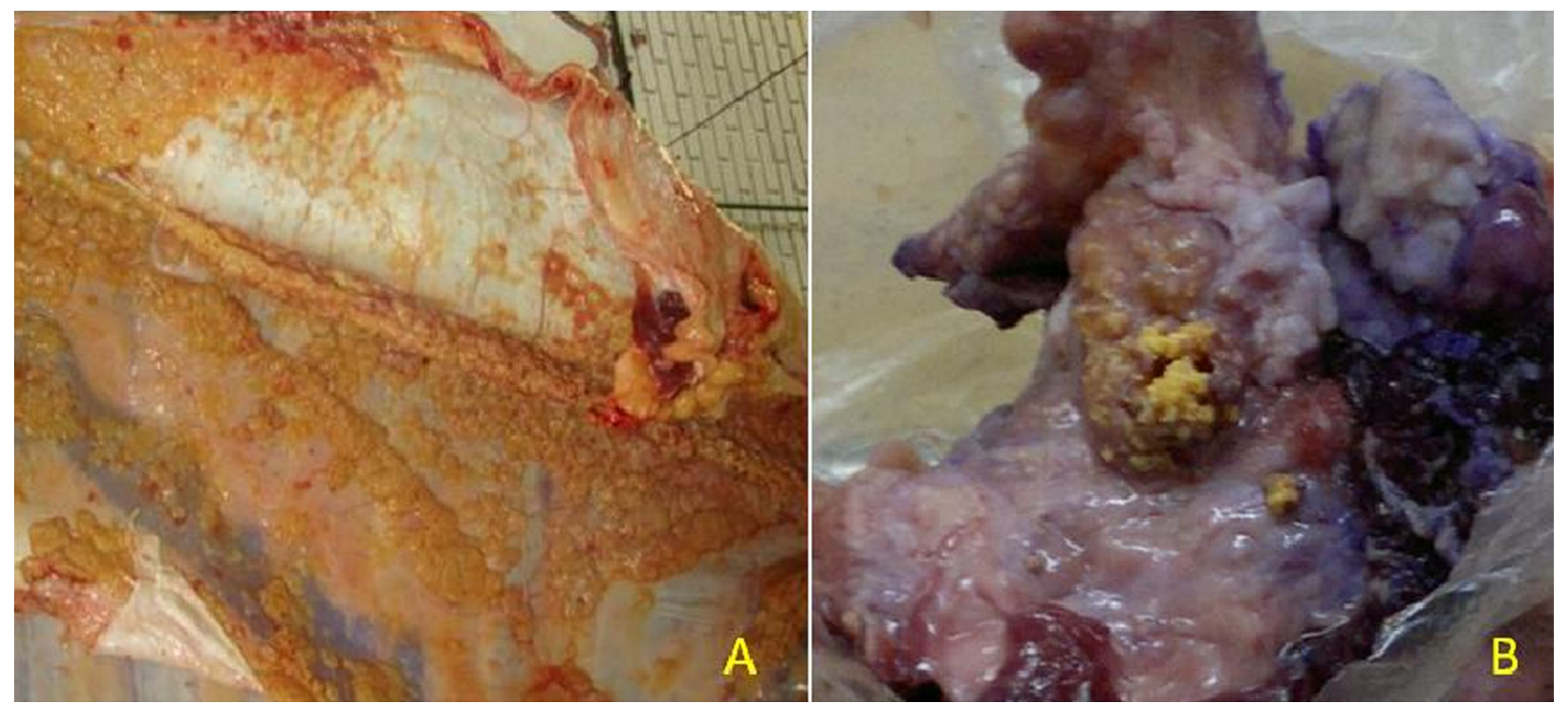

Fig.1. (A) Carcaça bovina condenada com lesões sugestivas de tuberculose bovina. (B) Pulmão com nódulos de aspecto caseoso. 
Os isolados identificados como Mycobacterium bovis foram submetidos ao método de spoligotyping, sendo identificados oito espoligotipos. Esses perfis estudados pelo Spoligotyping apresentaram deleções nos espaçadores 3, 9, 16 e 39-43. Foram discrimidados três clusters genéticos (SB 0121, SB 0295 e SB 1055) e cinco espoligotipos individuais, sendo sete descritos na literatura internacional e um genotipo inédito (Quadro 1).
121 foi o mais frequente no presente estudo (36\%), com um cluster com 5 isolados e observados em 4 municípios baianos. Foi descrito como o mais frequente no Brasil $(29,1 \%)$ e México (11\%) e ainda não foi discriminado na Argentina (Rodriguez et al. 2004, Zanini et al. 2005, Parreiras et al. 2012, Zumárraga et al. 2012). Também é frequente em países como França, Itália, Bélgica e África do sul, bem como em outros países que comercializam gado

Quadro 1. Caracterização molecular de isolados de Mycobacterium bovis provenientes de carcaças de bovinos abatidos em matadouros-frigoríficos. Brasil, 2012

\begin{tabular}{|c|c|c|c|}
\hline $\begin{array}{c}\text { Padrão do } \\
\text { espoligotipo* }\end{array}$ & Perfil do espoligotipo** & Isolados(\%) & $\begin{array}{l}\text { Município de } \\
\text { procedência }\end{array}$ \\
\hline SB0 121 & 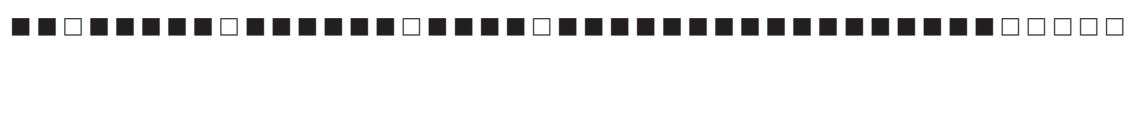 & $5(36)$ & $\begin{array}{c}\text { Euclides da Cunha - BA } \\
\text { Ipirá - BA } \\
\text { Pojuca - BA } \\
\text { Serrinha - BA }\end{array}$ \\
\hline SB2 95 & 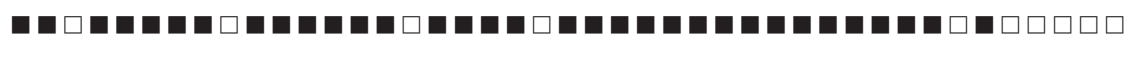 & $2(14)$ & $\begin{array}{c}\text { Alagoinhas - BA } \\
\text { Glória - BA }\end{array}$ \\
\hline SB1 145 & 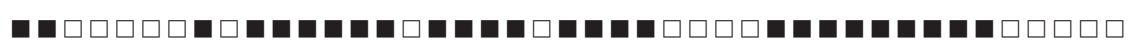 & $1(7,2)$ & Alagoinhas - BA \\
\hline SB0 140 & 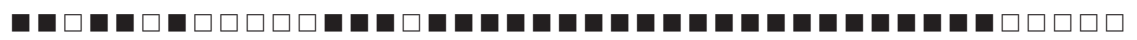 & $1(7,2)$ & Santo Antônio de Jesus - BA \\
\hline SB1 648 & 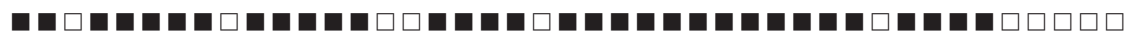 & $1(7,2)$ & Baianópolis - BA \\
\hline SB0 828 & 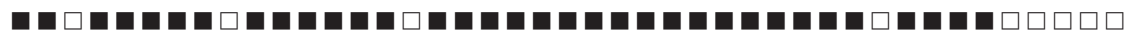 & $1(7,2)$ & Baianópolis - BA \\
\hline EG- BA1 2*** & 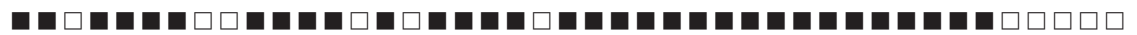 & $1(7,2)$ & Itabaianinha - SE \\
\hline
\end{tabular}

* Nome internacional atribuído pelo Mbovis.org. ** Caixas pretas e brancas indicam a presença e ausência, respectivamente, do espaçador específico na posição1-43, no locus de repetição direta. ${ }^{* * *}$ Novo espoligotipo encontrado e que foi nomeado pelos autores.

\section{DISCUSSÃO}

Em relação à distribuição das lesões na carcaça, foi constatado a ocorrência no parênquima pulmonar e nos linfonodos da cabeça e mediastinais em 75\% (135/180) do total. Dados similares aos observados por Gathogo et al. (2012), que inspecionaram 929 carcaças em dois abatedouros no Kênia e observaram que as lesões distribuídas nas carcaças estavam localizadas nos gânglios linfáticos brônquicos e mediastinais, parênquima pulmonar, parênquima hepático e linfonodos localizados em outros tecidos.

No exame bacteriológico dos fragmentos de lesões provenientes de bovinos abatidos, os resultados foram compatíveis com a literatura, sendo relatado crescimento das primeiras colônias de $M$. bovis em meio Stonebrink-leslie de 21 dias (Cousins et al. 1989), 36 dias (Corner 1994) e 28 dias (Mota et al. 2001). Segundo Corner (1994), o diagnóstico bacteriológico é considerado "padrão ouro", apesar de requerer um longo período para o crescimento das primeiras colônias e identificação da espécie. Desta forma, a m-PCR permitiu a identificação de Mycobacterium bovis de forma rápida e simples e, levando-se em conta a sua elevada especificidade, a técnica poderia auxiliar os programas de controle e erradicação da tuberculose.

Com o recente desenvolvimento dos processos de genotipagem, o método spoligotyping permite conhecer a diversidade genotípica do complexo $M$. tuberculosis e essa técnica permitiu identificar polimorfismo entre isolados de M. bovis em bovinos abatidos em matadouros-frigoríficos do Estado da Bahia e constitui-se numa ferramenta indispensável para apoiar sistemas de vigilância epidemiológica para detecção de focos de tuberculose. 0 espoligotipo SB com esses países (Haddad et al. 2001, Michel et al. 2008, Boniotti et al. 2009). Em Portugal, Duarte et al. (2008) encontraram uma frequência de $26,29 \%$, sendo isolados em bovinos e veados e está distribuído em todas as regiões em que há tuberculose. Na Espanha, esse perfil apresenta uma frequência de 29,6\% dos isolados (Rodriguez et al. 2010).

Os espoligotipos SB0295 e SB1055 formaram os outros 2 Clusters, com dois isolados cada. O SB0295 apresentou uma frequência de $24 \%$ e $0,4 \%$ de isolados no Brasil e Argentina, respectivamente (Zumárraga et al. 2012). Rodriguez et al. (2004) encontraram 25,6\% dos espoligotipos SB 0295 em 43 isolados de $M$. bovis provenientes de lesões sugestivas de tuberculose em bovinos abatidos no Estado de São Paulo. Enquanto Parreiras et al. (2012) relataram uma frequência de 29,5\% (18/61) de isolados em amostras de bovinos abatidos nos Estados do Amazonas, Distrito Federal, Mato Grosso do Sul, Minas Gerais, Santa Catarina e São Paulo. O SB295 foi descrito em Portugal e os isolados foram proevenientes de bovinos e javalis (Duarte et al. 2008). Rodriguez-Campos et al. (2011) relataram esse perfil como sendo o quinto mais frequente na Espanha, o que repesenta $4,1 \%$ dos isolados, sendo oriundo de bovinos, cervos e javalis. O espoligotipo SB1055 foi relatado por Parreiras et al. (2012) em 3,3\% dos isolados de bovinos abatidos em Matadouros-frigoríficos de Minas Gerais e de outras regiões brasileiras. Na Bahia, Costa et al. (2010) identificaram o perfil em $71,4 \%$ das amostras de bovinos abatidos na região metropolitana de Salvador, diferindo dos nossos resultados, que isolou o SB1055 em 14\% do isolados, além das amostras dos bovinos abatidos serem de regiões diferentes. Esse espoligotipo tem ampla distri- 
buição na América Latina, com registros no Brasil, Argentina, Paraguai, Uruguai, México e Costa Rica (Costa et al. 2010, Parreiras et al. 2012).

0 perfil SB1145 foi isolado em uma amostra proveniente de Alagoinhas-BA, sendo referido apenas no Brasil. Rodriguez (2005) identificou o espoligotipo em bovinos abatidos em São Paulo e em Minas Gerais, Parreiras et al. (2012) isolaram o SB1145 em 3,3\% (2/61) dos bovinos abatidos em matadouros-frigoríficos.

O SB0140 está presente em bovinos abatidos na Bahia e está amplamente difundido pela América latina, sendo identificado na Argentina, Paraguai, Uruguai e México (Haddad et al. 2001, Reyes et al. 2012, Zumárraga et al. 2012). Esse perfil também foi descrito na Austrália, Bélgica, França, Holanda, Irlanda, Reino Unido e Africa do Sul (www.mbovis.org). Na Itália, Boniotti et al. (2009) observaram uma baixa porcentagem do perfil, com $0,4 \%$ dos isolados. Gibson et al. (2004) relataram 15 casos de tuberculose humana no Reino unido, no período de 1997 a 2000, foi devido ao perfil SB0140. Rodriguez et al. (2004) obseravaram uma frequência de $16 \%$ dos isolados em bovinos abatidos em São Paulo.

O espoligotipo SB828 foi identificado em uma amostra, enquanto Boniotti et al. (2009), na Itália, relataram o espoligotipo em seis amostras. Também foi relatado na França e Espanha (www.mbovis.org). O espoligotipo SB1648 $(7,2 \%)$ foi referido apenas na Dinamarca (www.mbovis. org) e no presente estudo, um novo espoligotipo obtido foi classificado provisoriamente como espoligotipo EG-BA12.

Esses resultados demonstram que na Bahia existem compartilhamento de espoligotipos (SB295, SB121, SB1055, SB1145 e SB140) com outros estados brasileiros, São Paulo e Minas Gerais, como em outros Países como Argentina, México, Inglaterra, Espanha, Portugal e França. Enquanto que outros perfis (SB1648 e SB828) não foram relatados ainda no Brasil, mas foram discriminados na Europa.

A tipificação genética de isolados de $M$. bovis é uma técnica valorosa para a investigação epidemiológica, permitindo compreender a atuação dos reservatórios silvestres, identificação das regiões com perfis semelhantes de espoligotipos e na detecção dos focos de tuberculose bovina, principalmente em áreas de baixa prevalência (Rodriguez et al., 2004, Collins 2011). Essa diversidade genética dos isolados de $M$. bovis provenientes de carcaças de bovinos na Bahia sugere que a movimentação de animais entre propriedades, regiões ou países é um importante fator para a transmissão da tuberculose bovina. Segundo Figueiredo et al. (2011), ao caracterizarem epidemiologicamente a tuberculose em um rebanho bovino, relataram que a elevada diversidade de estirpes de $M$. bovis sugere a introdução de animais infectados proveniente de várias regiões geográficas.

\section{CONCLUSÕES}

A discriminação molecular pela técnica do spoligotyping permitiu identificar o polimorfismo entre os isolados de Mycobacterium bovis de bovinos abatidos no Estado da Bahia, sendo o espoligotipo SB121 o mais frequente.

Essa técnica, associada aos exames post mortem e bacteriológico permitiu um diagnóstico rápido dos isolados, além de contribuir para investigação epidemiológica da tuberculose bovina, disponibilizando informações que auxiliarão os órgãos de vigilância sanitária no desenvolvimento de estratégias para o seu controle, além da detecção de novos focos de tuberculose no Estado da Bahia.

Agradecimentos.- Ao Conselho Nacional de Desenvolvimento Científico e Tecnológico (CNPq) pelo suporte financeiro.

\section{REFERÊNCIAS}

Araújo C.P. 2004. Isolamento de Mycobacterium bovis em cultura e sua identificação pela reação de polimerase em cadeia. Dissertação de Mestrado, Universidade Federal de Mato Grosso do Sul, Campo Grande, MS. 52p.

Biffa D., Bogale A. \& Skjerve E. 2010. Diagnostic efficiency of abattoir meat inspection service in Ethiopia to detect carcasses infected with $M y$ cobacterium bovis: Implications for public health. BMC Public Health 10:462-474

Boniotti M.B., Goria M., Loda D., Garrone A., Benedetto A., Mondo A., Tisato E., Zanoni M., Zoppi S., Dondo A., Tagliabue S., Bonora S., Zanardi G. \& Pacciarini M.L. 2009. Molecular typing of Mycobacterium bovis strains isolated in Italy from 2000 to 2006 and evaluation of variable-number tandem repeats for geographically optimized genotyping. J. Clin. Microbiol. 47:636-644.

Brasil 2006. Manual Técnico do Programa Nacional de Controle e Erradicação da Brucelose e Tuberculose Animal (PNCEBT). Ministério da Agricultura, Pecuária e Abastecimento, Brasília, DF. 188p.

Brasil 2008. Manual Nacional de Vigilância Laboratórial da Tuberculose e outras Micobacterias. Departamento de Vigilância Epidemiológica, Secretaria de Vigilância em Saúde, Ministério da Saúde, Brasília, DF. 436p.

Cardoso M.A., Cardoso R.F., Hirata R.D.C., Hirata M.H., Leite C.Q.F., Santos A.C.B., Siqueira V.L.D., Okano W., Rocha N.S. \& Lonardoni V.C. 2009. Direct detection of Mycobacterium bovis in bovine lymph nodes by PCR. Zoonoses Publ. Health 56:465-470.

Collins D.M. 2011. Advances in molecular diagnostics for Mycobacterium bovis. Vet. Microbiol. 151:2-7.

Corner L.A. 1994. Post mortem diagnosis of Mycobacterium bovis infection in cattle. Vet. Microbiol. 40:53-63.

Cousins D.V., Francis B.R. \& Gow B.L. 1989. Advantages of a new agar medium in the primary isolation of Mycobacterium bovis. Vet. Microbiol. 20:89-95.

Costa A.C.F., Silva N.S., Rocha V.C.M., Rodrigues C.A.R., Estrela-Lima A., Moreira E.L.T., Madruga C., Arruda S.M., Ferreira Neto J.S., Silva M.C.A. \& Oliveira E.M.D. 2010. Tipificação genética, através da técnica de Spoligotyping, de isolados de Mycobacterium bovis em animais abatidos na região metropolitana de Salvador, Bahia, Brasil. Arqs Inst. Biológico, São Paulo, 77:233-237.

Costa L.B. 2012. Caracterização da tuberculose bovina em regiões de relevância econômica no Estado da Bahia. Dissertação de Mestrado, Escola de Medicina Veterinária, Universidade Federal da Bahia, Salvador. 121p.

De La Rua-Domenech R. 2006. Human Mycobacterium bovis infection in the United Kingdom: incidence, risks, control measures and review of the zoonotic aspects of bovine tuberculosis. Tuberculosis 86:77-109.

Duarte E.L., Domingos M., Amado A. \& Botelho A. 2008. Spoligotype diversity of Mycobacterium bovis and Mycobacterium caprae animal isolates. Vet. Microbiol. 130:415-421.

Figueiredo E.E.S., Ramos D.F., Medeiros L., Silvestre F.G., Lilenbaum W., Silva J.T., Paschoalin V.M.F. \& Dellagostin O.A. 2011. Multiple strains of Mycobacterium bovis revealed by molecular typing in a herd of cattle. Veterinary J. Doi:10.1016/j.tvjl.2011.11.006.

Gathogo S.M., Kuria J.K.N. \& Ombui J.N. 2012. Prevalence of bovine tuberculosis in slaughter cattle in Kenya: a postmortem, microbiological and DNA molecular study. Trop. Anim. Health Prod. 44:1739-1744.

Gibson A.L., Hewinson G., Goodchild T., Watt B., Story A., Inwald J. \& Drobniewski F.A. 2004. Molecular epidemiology of disease due to Mycobacterium bovis in humans in the United Kingdom. J. Clin. Microbiol. 42:431-434. 
Haddad N., Masselot M. \& Durand B. 2004. Molecular differentiation of Mycobacterium bovis isolates. Review of main techniques and applications. Res. Vet. Sci. 76:1-18.

Haddad N., Ostyn A., Karoui C., Masselot M., Thorel M.F., Hughes S.L., Inwald J., Hewinson R.G. \& Durand B. 2001. Spoligotype diversity of Mycobacterium bovis strains isolated in France from 1979 to 2000. J. Clin. Microbiol. 39:3623-3632.

Heinemann M.B., Mota P.M.P.C., Lobato F.C.F., Leite R.C. \& Lage A.P. 2008. Tuberculose bovina: uma introdução à etiologia, cadeia epidemiológica, patogenia e sinais clínicos. Cad. Téc. Vet. Zootec. 59:1-12.

IBGE 2010. Efetivos dos rebanhos de grande porte em 31.12.2010, segundo as Grandes Regiões e Unidades da Federação. Instituto Brasileiro de Geografia e Estatística, Brasília, DF. Disponível em <http://www.ibge. gov.br/home/estatistica/economia/ppm/2010/tabelas_pdf/tab03. pdf> Acesso em 29 set. 2012.

Kamerbeek J., Schouls L., Kolk A., Van Agterveld M., Van Soolingen D., Kuijper S., Bunschoten A., Molhuizen H., Shaw R., Goyal M. \& Van Embden J. 1997. Simultaneous detection and strain differentiation of Mycobacterium tuberculosis for diagnosis and epidemiology. J. Clin. Microbiol. 35:907-914.

Kantor I.N. \& Ritacco V. 2006. An update on bovine tuberculosis programmes in Latin American and Caribbean countries. Vet. Microbiol. 112:111-118.

Kremer K., Van Soolingen D., Frothingham R., Haas W.H., Hermans P.W.M., Martín C., Palittapongarnpim P., Plikaytis B.B., Riley L.W., Yakrus M.A., Musser J.M. \& Van Embden J.D.A. 1999. Comparison of methods based on different molecular epidemiological markers for typing of Mycobacterium tuberculosis complex strains: interlaboratory study of discriminatory power and reproductility. J. Clin. Microbiol. 37:2607-2618.

Lilenbaum W. 2000. Atualização em tuberculose bovina. Revta Bras. Med. Vet. 22:145-151.

McLernon J., Costello E., Flynn O., Madigan G. \& Ryan F. 2010. Evaluation of mycobacterial interspersed repetitive-unit-variable-number tandemrepeat analysis and spoligotyping for genotyping of Mycobacterium bovis isolates and a comparison with restriction fragment length polymorphism typing. J. Clin. Microbiol. 48:4541-4545.

Michel A.L., Hlokwe T.M., Coetzee M.L., Mare L., Connoway L., Rutten V.P.M.G. \& Kremer K. 2008. High Mycobacterium bovis genetic diversity in a low prevalence setting. Vet. Microbiol. 126:151-159.

Mota P.M.P.C., Lobato F.C.F., Assis R.A., Lage A.P. \& Parreiras P.M. 2001. Isolamento de Mycobacterium bovis em cão. Arq. Bras. Med. Vet. Zootec. 53:1-3.

Pacheco A.M., Hamzè A.L., Avanza M.F.B., Pereira D.M., Pereira R.E.P., Cipriano R.S. \& Lot R.F.S. 2009. Tuberculose bovina: relato de caso. Revta Cient. Eletr. Med. Vet. 7(13):1-4.

Parreiras P.M., Andrade G.I., Nascimento T.F., Oelemann M.C., Gomes H.M., Alencar A.P., Assis R.A., Mota P.M.P.C., Pereira M.A.S., Lobato F.C.F., Lage A.P. \& Suffys P.N. 2012. Spoligotyping and variable number tandem repeat analysis of Mycobacterium bovis isolates from cattle in Brazil. Mem. Inst. Oswaldo Cruz 107:64-73.

Reyes J.A.G., Casanova L.G., Torres C.R., Gallegos S.L.S., Alarcón G.J.C., Pezzat M.M., Martínez O.P., Chávez C.E. \& Suazo F.M. 2012. Population structure of Mycobacterium bovis isolates from cattle in Mexico. Prev. Vet. Med. 106:1-8.
Richards W.D. \& Wright H.S. 1983. Preservation of tissue specimens during transport to mycobacteriology laboratories. J. Clin. Microbiol. 17:393-395.

Rodriguez C.A.R., Zumárraga M.J., Oliveira E.M.D., Cataldi A.A., Romano M.I., Otto H.H., Bonafé V.L. \& Ferreira Neto J.S. 2004. Caracterização molecular de isolados de Mycobacterium bovis do Estado de São Paulo Brasil, utilizando a técnica de spoligotyping. Arqs Inst. Biológico, São Paulo, 71:277-282.

Rodriguez C.A.R. 2005. Sistema de detecção de focos de tuberculose bovina no Estado de São Paulo utilizando métodos moleculares e epidemiológicos. Tese de Doutorado, Faculdade de Medicina Veterinária e Zootecnia, Universidade de São Paulo, São Paulo. 86p.

Rodriguez S., Romero B., Bezos J., De Juan L., Alvarez J., Castellanos E., Moya N., Lozano F., González S., Sáez-Llorente J.L., Mateos A., Domínguez L. \& Aranaz A. 2010. Spanish network on surveillance and monitoring of animal tuberculosis. High spoligotype diversity within a Mycobacterium bovis population: clues to understanding the demography of the pathogen in Europe. Vet. Microbiol. 141:89-95.

Rodriguez-Campos S., Aranaz A., Juan L., Sáez-Llorente J.L., Romero B., Bezos J., Jiménez A., Mateos A. \& Dominguez L. 2011. Limitations of spoligotyping and variable-number tandem-repeat typing for molecular tracing of Mycobacterium bovis in a high-diversity setting. J. Clin. Microbiol. 49:3361-3364.

Van Embden J.D., Van Gorkom T., Kremer K., Jansen R., Van Der Zeijst B.A. \& Schouls L.M. 2000. Genetic variation and evolutionary origin of the direct repeat locus of Mycobacterium tuberculosis complex bacteria. J. Bacterial. 182:2393-2401.

Warren R.M., Gey Van Pittius N.C., Barnard M., Hesseling A., Engelke E., De Kock M., Gutierrez M.C., Chege G.K., Victor T.C., Hoal E.G. \& Van Helden P.D. 2006. Differentiation of Mycobacterium tuberculosis complex by PCR amplification of genomic regions of difference. Int. J. Tuberc. Lung Dis. 10:818-822.

WHO 2012. Tuberculosis. Fact Sheet no.104. World Health Organization, Genève. Disponível em <http://http://www.who.int/mediacentre/factsheets/fs104/en/index.html> Acesso em 28 set. 2012.

Zanini M.S., Moreira E.C., Lopes M.T.P., Oliveira R.S., Leão S.C., Fioravanti R.L., Roxo E., Zumárraga M., Romano M.I., Cataldi A. \& Salas C.E. 2001. Mycobacterium bovis: polymerase chain reaction identification in bovine lymphonode biopsies and genotyping in isolates from southeast Brazil by spolygotyping and restricion fragment length polymorphism. Mem. Inst. Oswaldo Cruz. 96:1-5.

Zanini M.S., Moreira E.C., Salas C.E., Lopes M.T.P., Barouni A.S., Roxo E., Telles M.A. \& Zumarraga M.J. 2005. Molecular typing of Mycobacterium bovis isolates from South-East Brazil by spoligotyping and RFLP. J. Vet. Med. B 52:129-133.

Zumarraga M.J., Arriaga C., Barandiaran S., Cobos-Marín L., De Waard J., Estrada-Garcia I., Figueiredo T., Figueroa A., Giménez F., Gomes H.M., Gonzalez-y-Merchand J.A., Macías A., Milián-Suazo F., Rodríguez C.A.R., Santillán M.A., Suffys P.N., Trangoni M.D., Zárraga A.M. \& Cataldi A. 2012. Understanding the relationship between Mycobacterium bovis spoligotypes from cattle in Latin American Countries. Res. Vet. Sci. <http:// dx.doi.org/10.1016/j.rvsc> Acessado 12 jul. 2012. 